\title{
CRITÉRIOS MÉTODOS E PARÂMETROS DE ATUAÇÃO NO ENTORNO E DE BENS TOMBADOS ISOLADOS PELO INSTITUTO DO PATRIMÔNIO HISTÓRICO E ARTÍSTICO NACIONAL: A VISIBILIDADE EM QUESTÃO
}

\author{
CRITERIA, METHODS AND PRATICE PARAMEIERS IN THE BUFFER ZONE OF \\ PROTECTED BUILDINGS BY THE INSTITUTODO PATRIMÔNIOHISTÓRICOE \\ ARTISTICONACIONAL: VISIBILITYINQUESTION
}

\author{
Cristiane V. Cabreira' \\ Arquiteta, Universidade Federal do Rio de Janeiro/ FAU-PROARQ, cristianecabreira@gmail.com. \\ Rosina Trevisan Ribeiro" \\ Arquiteta, Universidade Federal do Rio de Janeiro/ FAU-PROARQ, rosinatrevisan@gmail.com \\ Cláudia Barroso Krausell! \\ Arquiteta, Universidade Federal do Rio de Janeiro/ FAU-PROARQ, barroso.krause@gmail.com
}

\begin{abstract}
Regognized the historic buildings have been treated physically as static elements immersed in a changing context, causing damages and harm to its preservation. In this sense, there is an effort to stablish guidelines for the preservation of a buffer zone to consolidate a protection ring that minimizes the negative effects of urban transformations. However, it is observed that mosto $\mathrm{f}$ the methods used for delimitation of the buffer zone is based on the visibility and ambiance criteria, insufficient to prevent negative impacts on the building physical structure and increase de degradation material process. To listing such methods, this paper aims to critically analyse them according the aspects proposed by the Operational Guidelines, da UNESCO, and the Xi-an Declaration, both 2005. These documents consider that there is a gap in the criteria considered for buffer zone delimitation of historic buildings, once they should not be limited to visibility, but also the association of other contexts: material, economic, climatic, social and cultural. The review proposed allow discuss the methods used for buffer zones delimitation, pointing the need for the inclusion of new atributes that Will safeguard effectively the historic building.
\end{abstract}

Keywords: Buffer Zone, Delimitation Methods, IPHAN, Xi-an Declaration.

\section{Resumo}

Reconhecidamente os edifícios históricos vêm sendo tratados fisicamente como elementos estáticos imersos em um contexto em constante transformação, ocasionando danos e prejuízos à sua preservação. Neste sentido, há um esforço para o estabelecimento das diretrizes para preservação de um entorno a fim de consolidar um anel de proteção que minimize os efeitos negativos das transformações urbanas. No entanto, observa-se que a maioria dos métodos utilizados para delimitação do entorno se baseia nos critérios de visibilidade e ambiência, insuficientes para impedir os impactos negativos na estrutura física do edifício e o incremento no processo de degradação material. Ao elencar tais métodos, este artigo tem como objetivo analisar criticamente os mesmos à luz dos aspectos propostos pela Operational Guidelines da UNESCO e pela Declaração de Xi-an, ambas de 2005. Considera-se que há uma lacuna nos critérios considerados para delimitação do entorno de edifícios tombados, visto que não devem se limitar à visibilidade, mas também à associação de outros contextos: materiais, econômicos, climáticos, sociais e culturais. A análise crítica proposta permitirá problematizar as orientações metodológicas existentes para delimitação do entorno de bens tombados, indicando a necessidade da inclusão de novos atributos que resguardem efetivamente o edifício histórico.

Keywords: Entorno, Métodos de Delimitação, IPHAN, Declaração de Xi-an.

Introdução
O tema da delimitação do entorno de bens tombados é complexo e, apesar de ser um instrumento potencial para a proteção do patrimônio edificado, é pouco explorado no 
Brasil. É um tema com alto grau de indefinição tanto em seus significados como em sua regulação jurídica, cujo objeto não é objetivamente definido de forma absoluta e se concretiza de forma flexível e variável em função dos valores que a cada momento lhes são atribuídos. O entorno, no âmbito do objeto espacial de proteção que se configura, experimentou importantes variações em seu conteúdo, significados, valores e extensão espacial desde o início do século XIX nos procedimentos científicos de intervenção no Patrimônio Histórico.

Ruiz (1997), num esforço de delinear os pressupostos do conceito de entorno, o reconhece segundo dois âmbitos: sua condição de espaço circundante a todas as tipologias de bens imóveis de interesse cultural; e, portanto, sua caracterização como instrumento de proteção "ambiental” destes bens. Esta dupla dimensão existe segundo aspectos pouco claros e que podem conduzir a uma previsível confusão, ainda que a nível teórico, com outras categorias de bens imóveis como é o caso dos conjuntos históricos. Neste sentido, é importante considerar que o papel do entorno é potencializar o valor do monumento independente de possuir valor histórico ou não. Seu valor está, na verdade, na qualidade com que cumpre este papel.

No Brasil, segundo a atuação do Instituto do Patrimônio Histórico e Artístico Nacional - IPHAN, o valor atribuído ao entorno está diretamente relacionado com a capacidade que este tem de garantir a visibilidade do monumento tombado e de gerar para este um ambiente propício à sua fruição. Esta afirmativa tem por base, além do exame dos processos da instituição, a consideração de que o entorno se configura como

“a área de projeção localizada na vizinhança dos imóveis tombados, que é delimitada com o objetivo de preservar a sua ambiência e impedir que novos elementos obstruam ou reduzam sua visibilidade” (IPHAN, 2012a).

Tal relação e conceituação parecem emergir das teorias da percepção da imagem figurativa e acabam por considerar a composição da paisagem como um cenário de fundo do qual o monumento deverá se destacar e para onde as linhas de força deverão convergir. Tal critério de atribuição de valor se reflete nos métodos adotados para a delimitação do entorno e nos parâmetros adotados para controle das intervenções nesta área.

Tal abordagem reducionista é questionada nas discussões internacionais principalmente no que diz respeito à eficiência da proteção do bem tombado. Reconhece-se que é preciso assimilar contextos materiais, climáticos, econômicos e sociais aos critérios visuais até então preponderantes visando construir uma leitura avançada do tema segundo uma abordagem multicriterial.
Neste contexto, este artigo visa identificar os métodos predominantes na atuação do IPHAN $^{1}$ de maneira a permitir avaliar sua validade face ao disposto na Declaração de Xi-an e nas orientações da UNESCO. Os métodos $^{2}$ foram identificados a partir da obra de Carlos Danúzio Lima (In: MOTTA; THOMPSON, 2010), de um registro acerca da atuação do IPHAN no entorno de bens tombados publicado na década de 1980, do levantamento documental realizado por Lia Motta e Analucia Thompson visando subsidiar teoricamente os alunos do Programa de Especialização em Patrimônio do IPHAN/UNESCO em 2007, da consulta aos Processos de Entorno no Arquivo Central do IPHAN, seção Rio de Janeiro, entre julho e outubro de 2012, e da consulta de processos por amostragem cujas portarias de entorno encontram-se publicadas no sítio eletrônico do IPHAN. As amostras foram escolhidas segundo casos emblemáticos, recorrentemente citados em publicações, e segundo parâmetros de intervenção diferenciados constantes nas portarias de delimitação.

Ainda que sem pretensões de esgotar o assunto, a pesquisa permitiu elencar alguns métodos, identificar critérios considerados e parâmetros estabelecidos para controle da área do entorno. A partir de tal feito, procedeu-se a uma análise em acordo com os documentos internacionais citados a fim de avaliar se sua principal função de proteção é cumprida e, ainda que sem se configurar como objetivo principal da atuação, que outros critérios foram considerados na delimitação.

\section{Da vizinhança à ambiência: um discurso temporal sobre a atuação do Instituto do Patrimônio Histórico e Artístico Nacional - IPHAN na delimitação do entorno de bens tombados}

A análise da trajetória de atuação do IPHAN permite inferir a ampliação do conceito de visibilidade, citado explicitamente no Decreto-Lei $\mathrm{n}^{\circ} 25$, de 30 de novembro de 1937 (BRASIL, 1937) ${ }^{3}$, para o de vizinhança e posteriormente de ambiência na delimitação da área de influência de bens tombados. Lima (In: MOTTA; THOMPSON, 2010) destaca que a noção de vizinhança do monumento de valor cultural está explicitamente presente nas primeiras versões de redação do projeto de lei para a proteção do patrimônio. E que mesmo naquela ocasião se apresentava deficiente (LIMA, In: MOTTA; THOMPSON, 2010, p. 108).

Lima conclui que os aspectos cruciais da problemática da delimitação do entorno, termo que marca a evolução da noção de vizinhança, são aqueles de caráter subjetivo, na fruição da vizinhança do bem tombado, e de critérios 
técnicos que devem ser compatibilizados e não auto excludentes. $\mathrm{O}$ autor indica dois momentos distintos da prática de proteção do entorno: o primeiro caracterizado pela moção de processos jurídicos visando ao embargo de obras e interferências na vizinhança da coisa tombada com posterior elaboração de estudos técnicos que garantissem sua proteção; o segundo marcado pela atuação na delimitação do entorno de bens tombados com caráter preventivo. O primeiro momento coincidiria com as "memoráveis batalhas judiciais" (SANTANNA, 1995, apud MOTTA; THOMPSON, 2010, p. 26) e se refere aos primeiros anos após a criação do Instituto, concentrandose nas décadas de 1940 e 1950. O segundo momento, referenciado por Lima como posterior à década de 1970 se caracteriza pelo fortalecimento e diversificação do uso do entorno enquanto instrumento de proteção. Este período reflete-se de meados da década de 1960 até a década de 1980 (MOTTA; THOMPSON, 2010).

$\mathrm{Na}$ periodização proposta por Lia Motta e Analucia Thompson (2010) há ainda dois outros momentos característicos. O terceiro momento, marcado por um esforço no estabelecimento de procedimentos e normas internas para a institucionalização das ações no entorno, abrange especialmente a primeira metade da década de 1980. Marcado pela abertura política brasileira, o período é de relevante interesse para esta pesquisa. Reconhecido por técnicos do Instituto como um momento de proliferação de ações orientadas para a delimitação do entorno, houve um dispêndio de esforços no sentido de discutir as orientações adotadas até então que culminou na realização de dois seminários em 1983.

O "Primeiro Seminário Sobre Entorno de Monumentos Tombados”, realizado entre os dias 9 e 11 de março de 1983, na Casa de Ruy Barbosa, Rio de Janeiro, constituiu-se em uma iniciativa pioneira para a sistematização do debate visando ao aprofundamento das questões referentes à preservação da ambiência do bem tombado. Apesar da intenção, o documento final reflete a ausência de um conceito norteador e de diretrizes efetivas de abordagem caracterizando-se mais por uma orientação de processo administrativo. O segundo seminário foi realizado entre os dias 18 e 20 de outubro de 1983. Deste último identifica-se apenas o registro de uma avaliação feita por Ana Carmem Jara Jasco que considera não ter havido nenhum avanço significativo na discussão.

Cabe destacar no período a publicação da Portaria n ${ }^{0} 10$ e a Portaria $n^{0} 11$, ambas de 1986 , que versam sobre orientações acerca dos processos de aprovação de projetos dedicados a bens tombados ou nas áreas de seus respectivos entornos demandando minuciosos estudos para estes últimos. Além destes documentos, cabe citar a tentativa de criar os processos de Entorno com o respectivo Livro do Entorno a exemplo dos livros de tombamento.

O quarto momento estabelecido por Lia Motta e Analucia Thompson se estende de 1986 a 2003 não por uma característica peculiar, mas por ser um recorte investigativo-documental que tinha como objetivo analisar os impactos do debate e dos documentos resultantes no início da década de 1980 nos processos de tombamento e delimitação de seus respectivos entornos. Neste sentido buscavam-se os instrumentos utilizados que referenciavam o tema entorno de maneira a identificar os valores considerados e os mecanismos utilizados na sua delimitação. O levantamento realizado revelou que cerca de $25 \%$ dos processos de tombamento contava com a delimitação do entorno. Dos 80 processos dedicados a bens imóveis, 45 deles mencionavam 0 entorno, sendo que em 23 casos sua delimitação foi discutida. Nos 22 casos restantes foi feito algum tipo de referência ao entorno tratando-se de constatação de sua necessidade, porém sem nenhum avanço para seu estudo e delimitação.

No levantamento documental realizado destacam-se quatro critérios utilizados para a definição do entorno dos monumentos tombados: escala $(43,50 \%)$; contexto histórico-paisagístico (30,40\%); legal $(17,40 \%)$ e outros (9\%). O critério de escala refere-se a áreas que perderam ou não possuem relação estilística com o monumento ou sejam de natureza tipológica distinta. O critério do contexto histórico-paisagístico visa resgatar as "relações históricas ou paisagísticas do entorno com esse bem, de forma que as características históricas aí presentes ainda contribuam para contar a história do lugar" (MOTTA; THOMPSON, 2010, p. 75). O critério legal foi atribuído aos processos cuja delimitação do entorno partiu de uma demanda legal. Neste caso incluem-se tombamentos onde, por exemplo, foi definido um raio de proteção sem justificativas devidamente embasadas para sua abrangência. Os critérios demarcados como 'outros' se referem a dois casos peculiares que não consideraram somente aspectos de visibilidade. Tal destaque mostra que a consideração de outros critérios que não a visibilidade ou o seu alargamento, a percepção do monumento na paisagem, ainda são tidos como incomuns e como exceção em uma regra consolidada no Instituto.

No contexto deste artigo, entende-se que o quarto período estende-se aos dias atuais e que se caracteriza por um incremento na forma de abordagem com novos métodos e abordagens de delimitação.

\section{A visibilidade como critério: métodos de delimitação do entorno de bens tombados}




\section{pelo Instituto do Patrimônio Histórico e Artístico Nacional - IPHAN}

Concluindo a partir da análise da utilização do instrumento do entorno como forma de proteção do patrimônio edificado e paisagístico brasileiro pelo IPHAN, Lia Motta e Analucia Thompson (2010) afirmam que não há um método institucionalizado em relação ao tema. A complexidade que a delimitação de um entorno implica conjugando legislação em esferas de governo diversas, aspectos jurídicos, planos urbanísticos, interesses econômicos e especulativos, diversos atores sociais, contextos múltiplos e a relação sempre conflitante entre o direito privado e o direito difuso, acaba por orientar ações "caso a caso". O que se observa é a conjugação de diferentes concepções de entorno em momentos distintos de atuação do órgão com o atendimento de demandas sociais e de decisões judiciais distintas. A cada processo deflagrado para delimitação do entorno é utilizado um método particular, não necessariamente anexado aos processos pertinentes, com pretensões de que seja uma diretriz para os demais.

A ausência de um método de delimitação institucionalizado é justificada sob diversos aspectos como, por exemplo, ausência de debates institucionais e lacunas na competência técnica sobre um tema que requer uma abordagem multidisciplinar. Apesar disso, é possível perceber uma predominância de métodos de delimitação do entorno baseados na apreensão da paisagem, geralmente fundamentados no atributo da visibilidade. A predominância refere-se à métodos reincidentes de certa forma abordados em grande parte dos processos ou àqueles que foram aplicados em objetos de grande impacto na paisagem das cidades. A partir da análise dos estudos e pareceres acerca da delimitação de entorno identificou-se os seguintes métodos: método das visuais ${ }^{4}$, cartografia histórica, análise visual urbana, unidades de paisagem e análise da morfologia urbana.

O método das visuais, termo emprestado da geometria descritiva com o objetivo de estabelecer um pensamento norteador para grande parte das ações do IPHAN nas áreas envoltórias desde o início de sua criação, zela pela identificação da relação visual mantida entre um ponto de interesse e sua percepção a partir de outros pontos a nível do observador. Pretende-se que a partir das relações visuais identificadas seja feita uma análise para estabelecer cenários de possíveis intervenções que desestabilizariam tal relação, permitindo indicar parâmetros para controle da mesma. Em uma primeira abordagem o resultado da aplicação do método geraria um perfil de fundo para o monumento, compondo com este quase uma imagem figurativa. $O$ método se baseia na percepção, não necessariamente na interpretação ${ }^{5}$ das imagens obtidas construídas de maneira a garantir a predominância do monumento em relação a seu entorno.

Considerando que a grande maioria dos bens tombados encontra-se imersa em ambientes urbanos transformados em relação à condição territorial de sua gênese, a aplicação do método das visuais não restabelece a relação visual contida em sua concepção. Ao representar a relação visual de um testemunho do passado com determinados valores previamente identificados com o seu contexto, visa garantir sua preponderância em relação aos demais elementos da cidade que o circundam com o objetivo único de permitir a sua leitura. O método pode ser exemplificado em diversos pareceres, uma vez que traduz o atributo orientador na ação do instituto: a visibilidade.

O caso da Igreja de Nossa Senhora da Glória no Outeiro ${ }^{6}$ é colocado por Lucio Costa como "um dos problemas paisagísticos mais importantes da cidade" (COSTA, 1943, apud MOTTA; THOMPSON, 2010, p. 28-29) (Figura 1). Influenciado pela Carta de Atenas, de 1933, Lucio Costa destaca não só a inconveniência de que novas construções sejam erguidas na encosta do outeiro, mas que também sejam demolidos "os velhos prédios ali existentes, a fim de que a orla valorizada do outeiro, [...], se incorpore definitivamente aos jardins” (p. 29). Visavase construir uma paisagem "para servir como fundo de cenário, com sua encantadora igrejinha setecentista, à bela perspectiva de parques [...]” (p. 29). 

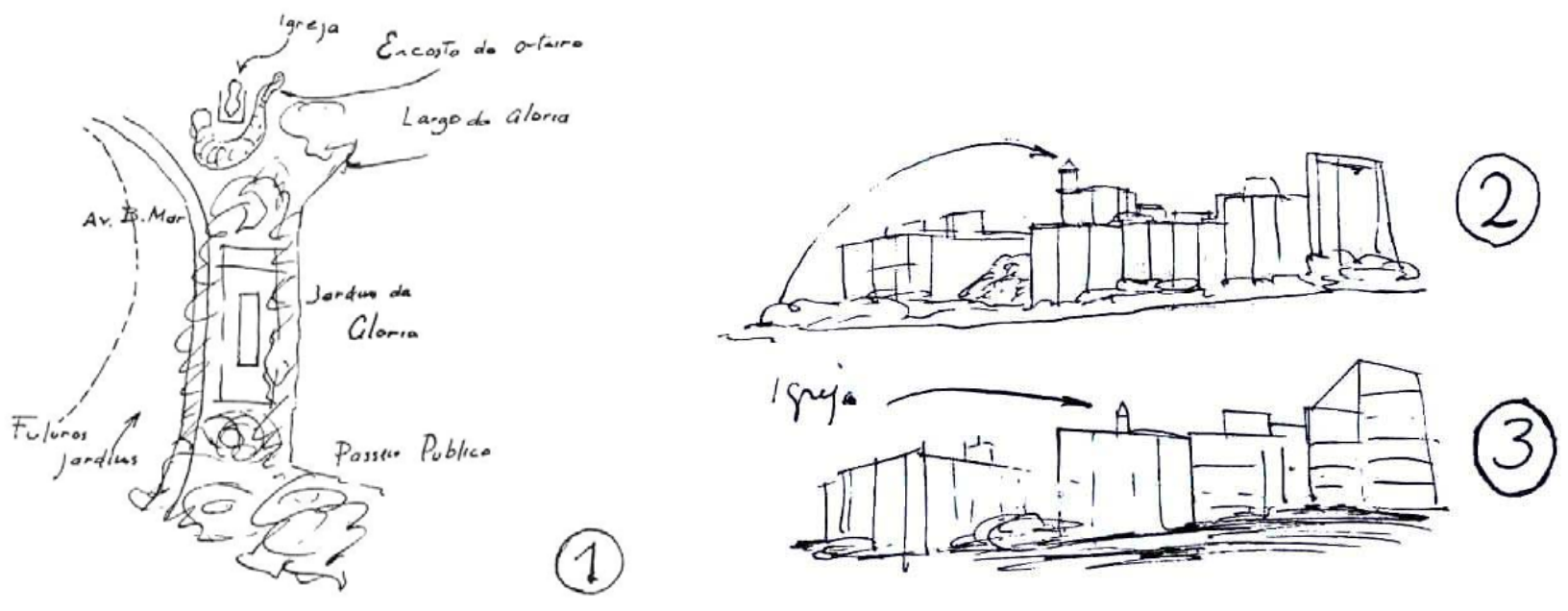

Figura 1. Conjunto de desenhos de Lúcio Costa simulando a ocupação da encosta e a consequente obstrução da visibilidade da Igreja de Nossa Senhora da Glória do Outeiro. Fonte: IPHAN, 2010.

Neste caso é possível inferir a preocupação com outro aspecto senão a visibilidade: a percepção do objeto na paisagem. O método das visuais foi, em alguns casos, abordado já impregnado da teoria da percepção da paisagem. Tratando-se de uma análise inteiramente subjetiva, a percepção da paisagem é entendida aqui como uma experiência sensorial do indivíduo com seu meio que o reconhece e o interpreta de forma própria. No entanto não se refere ainda à teoria de Kevin Lynch (1980) baseada em qualidades urbanas e conceitos de referência aplicados à experiência mental de um indivíduo. Trata-se de uma extensão do método das visuais onde o interesse não é somente no que se vê, mas como se vê o objeto tombado a partir de seu contexto ainda no âmbito da imagem figurativa. Desta forma de abordagem resulta, por exemplo, a preocupação com a aplicação de cores nas fachadas dos edifícios do entorno, como no caso do Reservatório de Mocó, Manaus-AM (processo aberto em 2011), a forma da cobertura e seus materiais nas edificações do entorno como no caso da Igreja de Nossa Senhora do Desterro, Pedra de Guaratiba-RJ (Portaria no 15, de 17 de outubro de 1986), dentre outros, de maneira a não destituir o monumento de uma atmosfera que se quer preservar ou mesmo criar.

O método da cartografia histórica trata de uma forma de leitura da cartografia urbana ${ }^{7}$. Neste método, através de mapas, cartas e plantas, é possível identificar o traçado urbano de determinadas regiões, a natureza dos espaços urbanos, a estrutura do quarteirão e dos lotes, a localização dos edifícios e de suas funções, a razão para escolha do sítio na implantação do conjunto urbano, bem como identificar as características físicas do sítio e suas relações com o território. Permite compreender o reflexo dos sucessivos períodos históricos no traçado urbano, os conceitos teóricos a ele subjacentes, sua gênese e períodos de desenvolvimento, a impressão das sucessivas experiências urbanísticas e as influências percebidas, dentre outros. Neste sentido, o método permite várias leituras com diferentes níveis de significado e aprofundamento. No entanto, trata-se de uma representação parcial da realidade que deve ser cotejada com outras fontes. (TEIXEIRA, 2000)

A aplicação do método pode ser observada no processo de delimitação do entorno da Igreja de Nossa Senhora da Pena, do Aqueduto Juliano Moreira, da Fazenda Engenho d’Água e da Fazenda da Taquara, localizados no bairro de Jacarepaguá, Rio de Janeiro. Ao estabelecer os pontos de visada entre os monumentos tombados e suas relações mútuas, buscava-se referências de seu desenvolvimento histórico e de sua condição urbana na ocasião do estudo. O valor simbólico do monumento foi estabelecido histórica e visualmente com suas áreas envoltórias. A partir da análise da configuração física, espacial e visual, relações topográficas e perspectivas relevantes, usos e significados das áreas, implicações sociais provenientes e motivadoras desses sistemas, e conexões e dependências estabelecidas com a cidade, o estudo resultou na delimitação de três áreas envoltórias de proteção que mantêm entre si uma relação de causalidade, historicidade e legibilidade (ARNAUT, 1986).

O método da análise visual urbana almeja identificar a lógica condicionadora das qualidades estéticas urbanas através da compreensão das imagens, das relações estabelecidas entre elementos de um conjunto e da emoção que transmitem. Fortemente influenciado pela obra de Kevin Lynch (1980) e pelo conceito de Paisagem Urbana introduzido por Gordon Cullen (1993), o método da análise visual urbana trata de uma abordagem subjetiva orientada pela percepção que o indivíduo tem 
da cidade. Apesar de cada indivíduo ter uma determinada percepção, existe uma imagem pública, comum, constituída a partir da sobreposição de várias percepções.

A influência deste método na delimitação do entorno de bens tombados se deu no estudo para a cidade de Sabará, Minas Gerais. O estudo foi desenvolvido no âmbito do Programa de Especialização em Patrimônio IPHAN/ UNESCO $^{8}$. Segundo Arrelaro (2008, p. 2), a delimitação se baseou na "relação visual do imóvel com a cidade e na relação cultural deste bem com outras formas de expressão (religião, tradições, etc.)”. O método baseia-se na valoração do entorno segundo quatro critérios distintos: (a) a importância do monumento e seu entorno na configuração urbana de Sabará - critério de ambiência, (b) valor histórico e/ ou artístico do bem isoladamente e de seus conjuntos - critério de valor excepcional do bem, (c) a importância como marco histórico da cidade e da memória da população - critério de percepção e apropriação da paisagem urbana, (d) a importância do traçado urbano como eixo de manifestações culturais - critério da relação entre os espaços e as manifestações culturais. Uma primeira etapa baseou-se na análise cartográfica da área tombada como um primeiro exercício de delimitação, seguida de uma etapa exploratória visando confirmar o perímetro delimitado a partir da identificação dos sítios que não tinham interesse para integração da paisagem natural e urbana do entorno. Os critérios estabelecidos permitiram mapear as rotas culturais relacionadas com a área tombada (Figura 2), mais especificamente centradas nas manifestações religiosas traduzidas nos percursos das procissões, manifestando uma primeira forma de abordagem do patrimônio imaterial no entorno de bens tombados. (ARRELARO, 2008).

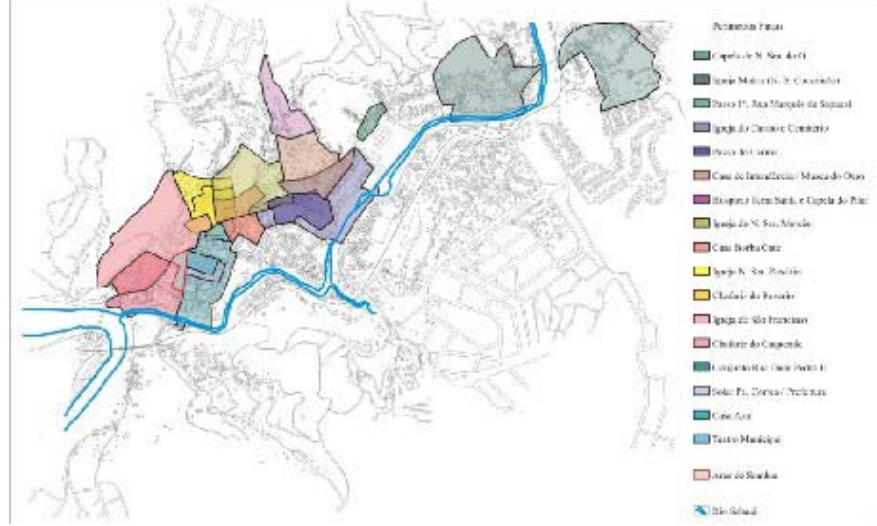

Figura 2. Planta geral de Sabará com a demarcação dos perímetros finais de entorno para todos os bens culturais. Fonte: ARRELARO, 2008.

O mesmo método também foi utilizado para subsidiar a Fundação Oswaldo Cruz, sob cuja tutela está o Núcleo Arquitetônico e Histórico de Manguinhos, no Rio de Janeiro, na elaboração do Plano de Preservação da Área de Interesse Histórico e Paisagístico. Para uma leitura sistêmica da área foram determinadas quatro áreas de interesse dotadas de caráter e identidades próprias. Concentrando-se no critério da legibilidade patrimonial do núcleo histórico, o método aplicado aliou programas de representação e a análise da paisagem urbana à valoração dos bens e à análise das interferências visuais. Buscando identificar as qualidades visuais de cada núcleo e sua influência mútua foram analisadas as características morfológicas e tipológicas do conjunto natural e urbanístico, as relações visuais entre as edificações e sua área envoltória. A partir da identificação dos marcos visuais e seus percursos foram determinadas visadas privilegiadas analisadas segundo escalas diferenciadas e sua historicidade para apreensão do conjunto tombado. A análise permitiu identificar ameaças à legibilidade patrimonial a partir dos impactos visuais, identificar a coesão ou fragmentação dos núcleos estabelecidos entre si e a coerência visual e harmonia entre o núcleo tombado e o restante do campus. (BORDE; SAMPAIO, 2012)

O método das Unidades de Paisagem tem como objetivo identificar partes do ambiente urbano com fisionomias peculiares que resguardam determinadas características e vocações. Franco (1997) define a Unidade da Paisagem como uma parte do Sistema de Paisagem por sua vez classificado de acordo com a topografia, solos, vegetação e intervenção antrópica correlacionadas com geologia, geomorfologia e clima. Trata-se de um recorte territorial que apresenta homogeneidade de configuração caracterizada pela disposição e dimensão similares dos quatro elementos definidores da paisagem: o suporte físico, a estrutura e padrão de drenagem, a cobertura vegetal e a forma de ocupação (BRASIL, 2006). A partir de sua identificação e caracterização detalhada, constituise de uma ferramenta de apoio à orientação de estratégias e instrumentos de ordenamento ou das políticas setoriais com maior incidência na paisagem.

A aplicação do método foi feita por Aline Silva (2006) na proposta para delimitação do entorno de bens tombados no antigo bairro do Recife, na cidade de Recife-PE, com sugestão de ampliação do tombamento do conjunto arquitetônico, urbanístico e paisagístico no âmbito do Programa de Especialização em Patrimônio do IPHAN/ UNESCO. A análise se orientou pelo critério da visibilidade e considerou os seguintes elementos: tipologia das edificações (gabaritos, implantação no lote, parcelamento), fachadas (coroamento - perfis), cobertura, espaços livres públicos (lineares - ruas e cais, não lineares - praças), traçado urbanístico e outros elementos tais como mar, rio e arrecifes. O estudo se traduziu em mapas, tabelas, gráficos e desenhos capazes de identificar as Unidades de Paisagem (Figura 3). (SILVA, 2006) 


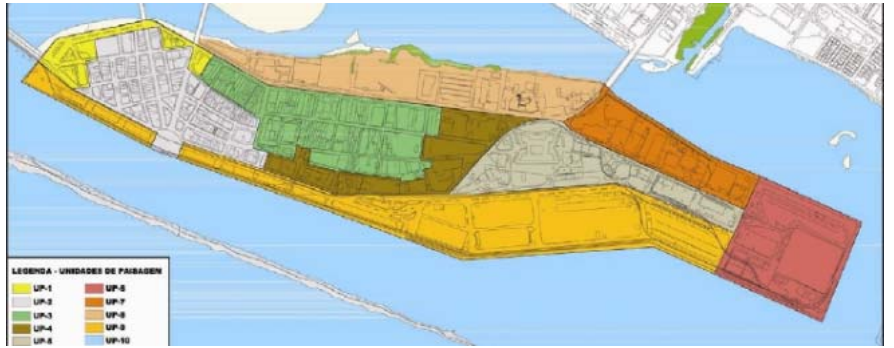

Figura 3. Mapa das Unidades de Paisagem do Bairro do Recife. Fonte: elaborado pela 5 a SR/ IPHAN, a partir de mapa-base da URB/ Unibase 2002, formatado por Rodrigo Cantarelli, apud SILVA, 2006.

Posteriormente o método foi aplicado pela mesma Secretaria Regional do IPHAN nos bairros de Santo Antônio e São José. Nos bairros estão localizados 16 monumentos tombados pelo IPHAN que, em 1984, aprovou a delimitação do polígono de entorno destes monumentos. A pressão imobiliária sofrida pela área demandou uma revisão da poligonal. Fundamentado no método aplicado por Silva (2006) buscou-se a identificação das unidades de paisagem enquanto "unidades tecno-crono-morfológicas” (LEAL; FREITAS, 2008), conjugando tempo, técnica e morfologia urbana. Neste caso a análise considerou os seguintes Elementos de Paisagem: lotes, edificações, quadras, ruas e espaços verdes. Como resultado foram identificadas seis Unidades de Paisagem, embora não tenha sido proposta uma nova poligonal de delimitação.

A análise da morfologia urbana, recorrente na prática mais recente do IPHAN, se desenvolve a partir da construção de um cenário possível a partir da análise da ocupação do lote e dos gabaritos permitidos pela legislação municipal no entorno do monumento tendo como referência o cenário existente. Fundamentado no atributo da visibilidade e da permanência da ambiência, os cenários estabelecidos permitem definir os parâmetros urbanísticos a serem então adotados na área.

Sua aplicação pode ser notada no processo dedicado ao entorno do Museu do Exército (Casa de Marechal Deodoro) e da antiga Casa da Moeda (atual Arquivo Nacional), na cidade do Rio de Janeiro, aberto em 1989. O entorno é divido em setores onde para cada um deles são atribuídos parâmetros de alinhamento, gabaritos e volumetria, cuja razão é manter a preponderância da Casa da Moeda em relação ao casario vizinho. Com isto visava-se garantir uma área de proteção visual para o elo de ligação entre a Avenida Presidente Vargas e o trecho antigo. O processo foi marcado pela existência de duas propostas de delimitação que, consideradas divergentes conceitualmente (IPHAN, 2010), ilustravam entendimentos distintos sobre o papel do entorno. A primeira, da $6^{\text {a }}$ Diretoria Regional (DR), atualmente $6^{\mathrm{a}}$ Secretaria Regional (SR), buscava adequar o contexto à realidade presente (Figura 4), enquanto que a segunda, da Coordenadoria de proteção, buscava resgatar o seu papel na malha urbana através da recontextualização histórica (Figura 5). A segunda proposta foi acatada.

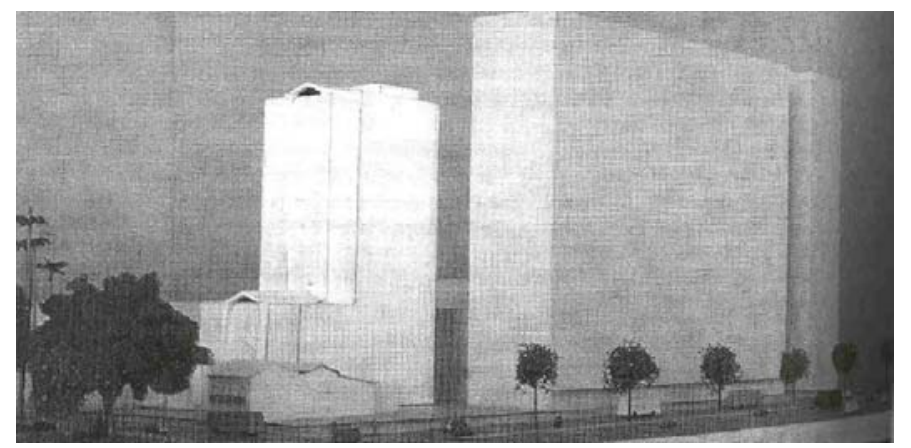

Figura 4. Estudo de volumetria do Tribunal Regional do Trabalho (TRT) na Avenida Presidente Vargas. Maquete. Proposta $6^{a}$ Diretoria Regional (DR), 1987. Arquivo Central do IPHAN/ Seção Rio de Janeiro. Slide. Fonte: IPHAN, 2010, p. 89.

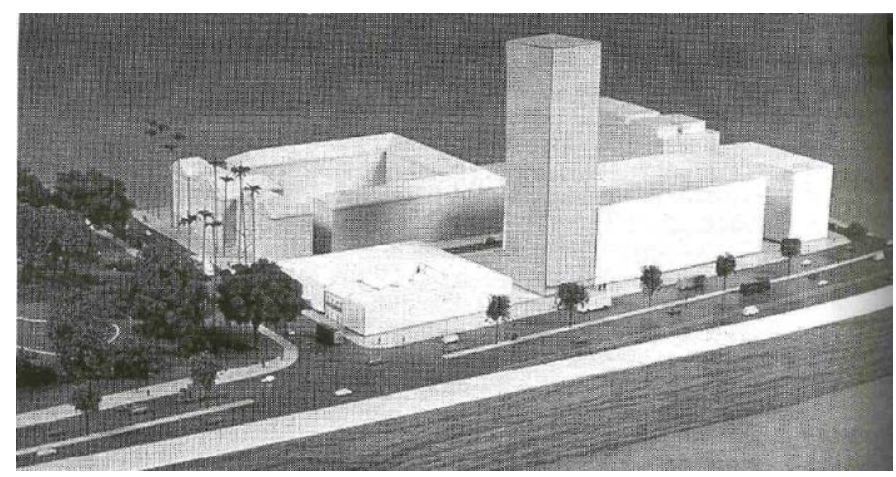

Figura 5. Estudo de volumetria do Tribunal Regional do Trabalho (TRT) na Avenida Presidente Vargas. Maquete. Proposta Coordenadoria de Proteção, 1987. Arquivo Central do IPHAN/ Seção Rio de Janeiro. Slide. Fonte: IPHAN, 2010, p. 89.

O método foi utilizado na delimitação do entorno do Reservatório de Mocó, Manaus, cujo processo foi aberto em 2011. Embora fosse cogitada a aplicação de uma circunferência de raio de 300 metros, esta mostrou-se insuficiente devido à configuração topográfica do sítio. $\mathrm{O}$ estudo foi orientado de maneira a incluir outras áreas cuja ocupação dos parâmetros limites permitidos pela legislação de uso e ocupação do solo vigente viesse a comprometer a relação de cheios e vazios fundamentais à compreensão destacada do monumento tombado. Os elementos analisados foram: cones visuais de aproximação ao monumento, áreas verdes e formas de fruição entre o espectador e o monumento. Foram eleitos quatro cones de visibilidade para os quais foram estabelecidos três cenários futuros a partir da ocupação possível. 


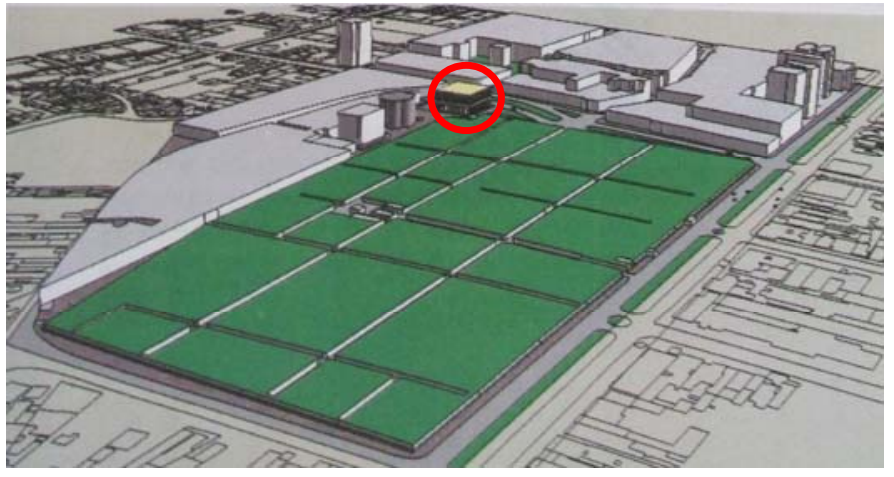

Figura 6. Proposta 03 - Cenário intermediário, ponderando as propostas 01 e 02, destacando o bem tombado. As áreas em verde referem-se ao cemitério cujos elementos também são preservados Fonte: IPHAN, 2011.

$\mathrm{Na}$ conclusão do estudo prevaleceu a proposta intermediária (Figura 6) por vislumbrar um acréscimo gradativo da massa construída à medida que se afasta do monumento tombado, configurando uma área de amortecimento que minimiza o impacto da massa construída no monumento. Tal estratégia já havia sido proposta por Lucio Costa, em 13 de março de 1959, no processo de tombamento das casas situadas à Rua do Carmo, $\mathrm{n}^{\circ} 46$ e 54, Rio de Janeiro. Neste processo registra a vizinhança nociva às casas, cujo arco e oratório são tombados, destacando a necessidade de um gabarito de transição abrangendo toda a quadra de maneira a garantir a unidade urbanística do conjunto de interesse.

\section{Uma síntese sobre atributos, métodos e parâmetros}

Visando a uma síntese sobre os métodos identificados, os critérios considerados e os parâmetros resultantes para controle das intervenções, apresenta-se um quadro contendo um resumo do levantamento realizado (Quadro 1).

Os critérios e parâmetros apresentados foram levantados a partir da análise dos processos de delimitação do entorno de bens tombados e das respectivas portarias que indicam as orientações para intervenções nas áreas de que tratam. Tais indicações não revelam uma restrição dos métodos, mas uma limitação na aplicação dos mesmos, pois, conforme sejam elencados critérios de entrada pode haver um refinamento dos parâmetros ou a incorporação de alguns outros.

O quadro síntese apresentado faz notar uma questão curiosa: independente do método e da combinação de critérios de entrada, a regulação da atuação no entorno de bens tombados se restringe aos mesmos parâmetros com algumas poucas variações. Tal observação é feita também com base na análise das portarias publicadas pelo IPHAN em seu sítio eletrônico e que tratam do entorno de bens tombados. O impacto do critério utilizado em um determinado método não está somente no parâmetro gerado, mas também e principalmente no índice de qualificação ou quantificação do mesmo.

\begin{tabular}{|c|c|c|}
\hline CRITÉRIO & MÉTODO & PARÂMETROS \\
\hline Visibilidade + ambiência & Método das visuais & $\begin{array}{l}\text { Gabarito, restrição na aplicação de sinalização para publicidade, } \\
\text { tratamento de fachadas. }\end{array}$ \\
\hline $\begin{array}{c}\text { Visibilidade + evolução } \\
\text { urbana }\end{array}$ & Cartografia histórica & $\begin{array}{l}\text { Gabarito, taxa de ocupação, restrição na aplicação de } \\
\text { sinalização para publicidade. }\end{array}$ \\
\hline $\begin{array}{c}\text { Visibilidade + apropriação } \\
\text { do espaço }\end{array}$ & Análise visual urbana & Gabarito, restrição na aplicação de sinalização para publicidade. \\
\hline $\begin{array}{l}\text { Visibilidade + formação } \\
\text { histórica e morfologia }\end{array}$ & Unidades de Paisagem & Não apresentados. \\
\hline Visibilidade + morfologia & Análise da Morfologia urbana & $\begin{array}{l}\text { Gabarito, taxa de ocupação, restrição na aplicação de } \\
\text { sinalização para publicidade. }\end{array}$ \\
\hline
\end{tabular}

Quadro 1. Quadro sintético dos métodos de delimitação de entorno aplicados pelo IPHAN, indicando critérios de entrada e os parâmetros resultantes para 0 controle das intervenções. Fonte: Elaborado pelo autor, 2013.

\section{Sobre o que não se vê: uma análise face à$$
\text { Declaração de Xi-an, de 2005, e da }
$$$$
\text { Operational Guidelines da Organização }
$$$$
\text { das Nações Unidas para a Educação, a }
$$$$
\text { Ciência e a Cultura - UNESCO da }
$$ consideração de outros critérios na}

\section{delimitação do entorno de bens tombados.}

O reconhecimento da necessária abordagem integrada entre os edifícios históricos e o contexto no qual estão imersos tem suscitado a discussão acerca do papel desempenhado pelo entorno e as zonas de amortecimento. Em muitos casos absorvidos pela malha 
urbana e alvo de um contexto em constante transformação, os edifícios tombados sofrem com danos e prejuízos à sua preservação oriundos de fontes localizadas além da poligonal de proteção. Neste sentido, o critério da visibilidade tem se mostrado insuficiente devendo ser assimilados outros contextos: materiais, climáticos, econômicos, sociais e culturais.

Documentos recentes oriundos dos organismos internacionais dedicados à preservação do patrimônio como a Operational Guidelines da UNESCO e a 'Declaração de Xi-an Sobre a Conservação do Entorno Edificado, Sítios e Áreas do Patrimônio Cultural', adotada pelos membros presentes no congresso do ICOMOS realizado em Xi-an, China, ambas de 2005, reconhecem tal postura e definem as diretrizes para preservação do ambiente histórico e contribuem para uma leitura avançada do tema propondo novas conexões com outros documentos e disciplinas. O entorno é tido como elemento fundamental visto que gera impactos na estrutura física do edifício e sua dinâmica de transformação geralmente incrementa o processo de degradação material. As relações entre o edifício e seu ambiente exterior e os efeitos recíprocos que ocasionam podem ser observados especialmente em áreas densamente construídas e ocupadas, onde os efeitos negativos da urbanização para o conforto térmico e a saúde da população e o impacto ambiental ocasionado por outras variáveis ambientais são facilmente perceptíveis.

A publicação da Operational Guidelines da UNESCO tem por objetivo facilitar a aplicação da Convenção do Patrimônio Mundial (1972) descrevendo procedimentos com vistas, dentre outros, à inscrição de bens na Lista do Patrimônio Mundial e na Lista do Patrimônio Mundial em Perigo e sua proteção e conservação. Trata-se de um documento periodicamente revisado que reflete as decisões do Comitê do Patrimônio Mundial. (UNESCO, 2011)

O Capítulo II do referido documento traz a definição dos limites para uma proteção eficaz e das então denominadas buffer zones (aqui traduzidas como zonas de amortecimento), destacando-as como condição essencial para proteção do bem. Enfatiza-se sua influência direta na preservação do patrimônio e a necessidade de estudos específicos que regulem sua extensão, características e usos apropriados. A zona de amortecimento é definida como uma área envolvente cujo uso e exploração estão sujeitos a restrições jurídicas de forma a reforçar a proteção do bem a que se refere. Exige-se também uma explicação clara sobre a influência desta zona na preservação do bem e, caso não tenha sido determinada, deve ser incluída uma declaração que indique as razões da não inclusão. Além de dar destaque à garantia das perspectivas visuais importantes, o documento considera incluir outras áreas ou atributos que desempenhem função significativa para o bem e sua proteção como, por exemplo, a utilização sustentável dos mesmos.

A análise do documento apresenta uma nova atribuição de valor ao entorno e às zonas de amortecimento de bens protegidos. Reconhece-se sua influência e seu potencial de transformação, cujos aspectos negativos necessitam de adequada mensuração e avaliação para garantia da integridade do bem. Tais aspectos abrem caminho, ainda que preliminarmente, para a intervenção nestes espaços com vistas à adequação ambiental de edifícios históricos possibilitando transformações que permitam controlar ou pelo menos monitorar os impactos da modificação do ambiente urbano ou rural do qual é parte e a proposição de estratégias que abarquem efeitos positivos na sua preservação e qualidade de vida.

A Declaração de Xi-an (ICOMOS, 2006), documento resultante da $15^{\mathrm{a}}$ Assembléia Geral do Icomos, recomenda, dentre outros, desenvolver instrumentos de planejamento e práticas para a conservação e a gestão do entorno, o acompanhamento e a gestão das mudanças que o ameacem e a inclusão das comunidades locais, interdisciplinares e internacionais para a cooperação e o fomento de uma consciência social sobre sua conservação e gestão. Admite-se a interação entre monumento e seu entorno segundo o ambiente natural e determina que "devem ser feitas avaliações do impacto ambiental de qualquer projeto que possa comportar um impacto sobre o significado das edificações, dos sítios e das áreas do patrimônio, assim como sobre seu entorno” (ICOMOS, 2006, Art. 8). O aspecto mais significativo desta declaração para o tema a que este artigo se propõe é o Artigo 11, que ao estabelecer que "a gestão deve definir as formas e as ações necessárias para avaliar, medir, evitar ou remediar a degradação, a perda de significado, ou a banalização e propor melhorias para a conservação, a gestão e as atividades de interpretação" (ICOMOS, 2006) abre caminho para a inserção de critérios ambientais na preservação de edifícios históricos.

À luz de tais documentos pode-se afirmar a necessidade da incorporação de outros critérios que não o de visibilidade ou outros a ele relacionados de maneira a propiciar uma proteção efetiva do bem. Um destes critérios é o ambiental, diretamente relacionado com as questões de ventilação, iluminação, insolação e conforto humano. Mesmo a forma de abordagem destes critérios é discutida, visto que deve ser alvo de uma abordagem sistêmica.

Embora os documentos aqui mencionados sejam constantemente citados nas portarias publicadas pelo IPHAN dedicadas à proteção do entorno de bens 
tombados, o que se nota é que tal feito reflete um compromisso burocrático sem um necessário compromisso prático na abordagem para delimitação. Tal observação não invalida o critério da visibilidade, mas problematiza a atuação no entorno de bens tombados centrada em um critério limitado, sem correlações ou não sistematizado com outras abordagens. Também não se trata da invalidação dos métodos aplicados. Conforme a configuração territorial, a permanência ou não de usos intrínsecos a um determinado território, a ocupação urbana do entorno, as características e valor do bem tombado e as orientações institucionais para atuação, um método se mostrará mais ou menos eficaz. No entanto, a necessidade de uma abordagem multicriterial inevitavelmente refletir-se-á no método a ser aplicado, uma vez que nem todos estão aptos para tal feito.

\section{Conclusão}

O esforço desprendido para descortinar a atuação do IPHAN - Instituto Nacional do Patrimônio Histórico e Artístico Nacional no entorno de bens tombados revelou a ausência de um método institucionalizado que oriente as ações do órgão, embora tenha sido identificado um consenso na consideração do critério da visibilidade para delimitação, bem como uma periodização calcada na ampliação da discussão acerca da aplicação do instrumento de proteção "entorno". Os critérios utilizados na delimitação do entorno de bens tombados em geral são equivalentes e ainda que a escolha do método a ser utilizado seja fortemente influenciada por eles, não há uma discussão institucional sobre a validade ou eficiência destes métodos conforme a condição do bem e sua contextualização. Tal condição impossibilita o estabelecimento de uma diretriz que oriente as ações do órgão no que diz respeito ao tema. Foi possível também identificar uma uniformização dos parâmetros de atuação, geralmente calcados na limitação do gabarito, das taxas de ocupação e do controle da publicidade, além de restrições no tratamento de fachadas.

A posição atual do IPHAN ao se valer do atributo de visibilidade do conjunto de interesse considera o controle da publicidade, a regulação do gabarito e a recomendação de materiais no entorno, sem refletir preocupação com o crescimento e adensamento das áreas limítrofes e o seu impacto ambiental. A análise para a delimitação do entorno é feita caso a caso, oficializada através de portarias. Esta flexibilidade acaba por ocasionar a falta de delimitação e de controle das intervenções realizadas no entorno.

A análise de critérios, métodos e parâmetros resultantes face aos documentos internacionais mais recentes que tratam da atuação no entorno de bens imóveis de relevância cultural e histórica revela a ineficiência na aplicação dos critérios no Brasil. A determinação de uma abordagem multicriterial e sistêmica considerando o todo, suas partes e as inter-relações existentes entre elas, conforme orientado pelos documentos internacionais, visa agregar aos critérios de legibilidade, visibilidade e ambiência, critérios de qualidade ambiental que possuem influência direta na caracterização do sítio, na sua conservação e uso. Reconhece-se a influência mútua entre entorno e edifício tombado com impactos na percepção da paisagem cultural.

Neste sentido, a atuação no entorno de edifícios históricos conclama a um desenho consoante ao planejamento ambiental da cidade visando a qualidade de vida e a qualidade ambiental, diretamente relacionado ao desafio atual da conservação urbana integrada. Este modelo, que visa resolver os graves problemas de mobilidade e acessibilidade urbana, almeja também a requalificação de áreas urbanas de interesse cultural e a manutenção das qualidades paisagísticas, históricas e arquitetônicas dos elementos protegidos. Este desenho, que deve potencializar os aspectos positivos do edifício e seu entorno, deve ser alvo de estudos aprofundados que considerem diversos critérios de abordagem e por sua vez resultem em parâmetros efetivos de controle.

Tal abordagem é fundamental para garantir a preservação do edifício nos aspectos de sua materialidade, uso e fruição.

\section{Notas}

(1) Ainda que os órgãos dedicados à preservação do patrimônio nas esferas estadual e municipal tenham desenvolvido critérios e métodos de atuação no entorno de bens tombados sob sua tutela, este artigo limita-se a análise da atuação do IPHAN por ser o órgão máximo federal dedicado ao tema. Assim sendo, abarca todo o território nacional em sua diversidade climática, tipológica, cultural, ambiental, social, econômica e histórica, permitindo construir uma narrativa que, ainda que sem pretensões de esgotar o assunto, apresente um panorama da prática de atuação no entorno de bens tombados no Brasil.

(2) Nesta análise não foram consideradas as características do entorno (historicidade, sobreposições de tempo, contextualização, etc.) ou dos bens culturais (tipologia, estado de conservação, uso, características construtivas, etc.), tampouco a validade dos parâmetros para atuação no entorno em determinada situação resultantes do método aplicado. Tais aspectos, ainda que cruciais para a compreensão do tema, tratam “do que” se delimita em detrimento “de como” se delimita, este último objeto deste artigo. 
(3) O fundamento legal para a atuação do IPHAN no entorno de bens tombados é o Artigo 18 do Decreto - Lei n 25 , de 30 de novembro de 1937 que organiza a proteção do patrimônio histórico e artístico nacional. (BRASIL, 1937).

(4) Este método, cujo termo é sugestionado pela forma de atuação do IPHAN na maioria dos processos de análise do entorno de bens tombados, não se refere ao método da análise visual (Visual Appraisal), fundamentada na teoria de Kevin Lynch e Gordon Cullen.

(5) O fato de a imagem ser considerada uma linguagem universal em especial no que diz respeito à aparente simultaneidade do reconhecimento de seu conteúdo e assimilação, alimenta o equívoco que muitas vezes se comete entre percepção e interpretação (JOLY, 1996). O reconhecimento de uma imagem não induz automaticamente à compreensão de sua mensagem, esta vinculada tanto ao seu contexto interno quanto ao de seu surgimento, bem como às expectativas e conhecimentos do espectador. Reconhecer os motivos da mensagem visual e sua interpretação são operações mentais complementares. Assim, Martine Joly comenta que “[...] a análise da imagem, inclusive da imagem artística, pode desempenhar funções tão diferentes quanto dar prazer ao analista, aumentar seus conhecimentos, ensinar, permitir ler ou conceber com maior eficácia imagens visuais” (JOLY, 1996, p. 47).

(6) A Igreja do Outeiro da Glória é tombada a nível federal (Processo 49 - T - 38) e inclui o conjunto urbano paisagístico denominado Praça Nossa Senhora da Glória, ou Jardins do Outeiro da Glória, projetado por Lucio Costa entre 1959 e 1965. Fundamentado no parecer de 1943, o projeto visava a conexão efetiva do edifício na paisagem da cidade e sua percepção em um contexto que criasse uma paisagem de fundo. (ANDRADE, 2012)

(7) O termo "urbana” utilizada referencia a cidade ou quaisquer de suas partes entendida como núcleo urbano de quaisquer dimensões.

(8) O programa é dedicado à formação de recém-graduados em várias disciplinas para atuarem no campo da preservação cultural. A cada curso é identificado um tema sobre o qual haja demanda no IPHAN. O curso que se refere especificamente o entorno de bens tombados é o projeto 914BRA4006, cujo Caderno de Estudos do PEP - Entorno de Bens Tombados foi publicado em 2007. (MOTTA, et al, 2010; ARRELARO, 2008)

\section{Referências}

ANDRADE, Inês El-Jaick. Dimensão Ambiental: o impacto do entorno em jardins de interesse histórico. Tese (Doutorado em Arquitetura) - Faculdade de Arquitetura e Urbanismo da Universidade de São Paulo, São Paulo, 2009.

ARNAUT, Jurema. Projeto de entorno de bens tombados em Jacarepaguá. Arquivo Central do IPHAN/ Seção Rio de Janeiro. Processo n ${ }^{\circ}$ 008-E-86/ SPHAN - RJ. Rio de Janeiro: IPHAN, 1986.

ARRELARO, Rafael. Paisagem Urbana do entorno a bens tombados: estudo da delimitação de perímetros para os bens tombados em Sabará/ MG. In: ARQUIMEMÓRIA, 3., 2008, Salvador. Anais... Salvador: IAB, UFBA, PPG-AU/ UFBA, 2008.1 CD-ROM.

BORDE, Andrea L. P.; SAMPAIO, Andrea R. Análise Visual do Conjunto Arquitetônico, Urbanístico e Paisagístico do campus Manguinhos da Fiocruz. In: SEMANA FLUMINENSE DE PATRIMÔNIO, 2., 2012, Vassouras. Anais... Vassouras: Arquivo Público do Estado do Rio de Janeiro, COC/ FIOCRUZ, FCRB, INEPAC-RJ, IPHAN/ 6a SR, MAST, Museu do Meio Ambiente, Museu Nacional, 2012.

BRASIL. Decreto - Lei n ${ }^{\circ}$ 25, de 30 de novembro de 1937. Disponível em: <http://www.planalto.gov.br/ccivil_03/decretolei/del0025.htm>. Acesso em: 15 dezembro 2012.

Projeto ORLA: Manual de Gestão. Brasília: MMA, 2006.

CULLEN, Gordon. Paisagem Urbana. São Paulo: Edições 70, 1993.

FRANCO, Maria de Assunção Ribeiro. Desenho Ambiental: uma introdução à arquitetura da paisagem com o paradigma ecológico. São Paulo: Annablume, 2008.

ICOMOS - CONSELHO INTERNACIONAL DE MONUMENTOS E SÍTIOS. Declaração de Xi-an sobre a conservação do entorno edificado, sítios e áreas do patrimônio cultural. Tradução ICOMOS/ Brasil. Xi-An: ICOMOS, 2006. The world heritage convention and the buffer zone. Recommendations for ICOMOS. World Report 2006-2007. Disponível em: < http://www.international.icomos.org/risk/world_report/2006-2007/pdf/H@R_20062007_47_Thematic_Report_WH_Convention_Buffer_Zone.pdf $>$. Acesso em: 15 dezembro 2012.

IPHAN - INSTITUTO DO PATRIMÔNIO HISTÓRICO E ARTÍSTICO NACIONAL. O que é entorno? Disponível em <http://portal.iphan.gov.br/montarDetalheConteudo.do;jsessionid=7DAB0D0470597AF333107BE29656972A?id=12697\& sigla=PerguntasFrequentes\&retorno=detalhePerguntasFrequentes $>$. Acesso em: 21 novembro 2012. 2012a.

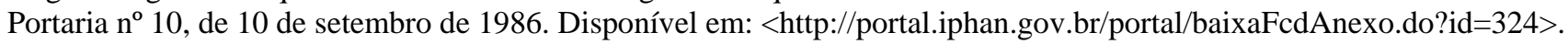
Acesso em: 17 dezembro 2012.

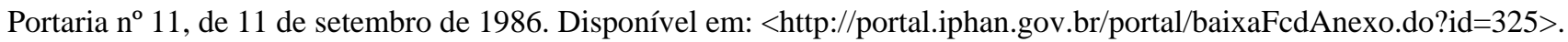
Acesso em: 17 dezembro 2012.

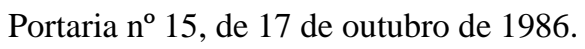

$\overline{\text { JOLY }}$, Martine. Introdução à análise da imagem. Campinas: Papirus, 1996.

LEAL, Thalianne de Andrade; FREITAS, Marcelo de Brito Albuquerque Pontes. Revisão do polígono de entorno dos monumentos tombados pelo IPHAN nos bairros de Santo Antônio e São José, Recife - PE. In: ARQUIMEMÓRIA, 3., 2008, Salvador. Anais... Salvador: IAB, UFBA, PPG-AU/ UFBA, 2008. 1 CD-ROM. 
LYNCH, Kevin. A imagem da cidade. São Paulo: Martins Fontes, 1980.

MOTTA, Lia; THOMPSON, Analucia. Entorno de bens tombados. Rio de Janeiro: IPHAN/ DAF/ Copedoc, 2010.

RUIZ, José Castillo. El entorno de los biene inmeubles de interes cultural. Tesi (Doctoral) - Instituto Andaluz del Patrimonio Cultural, Universidad de Granada, Granada, 1997.

SILVA, Aline de Figuerôa. Proposta de Delimitação do polígono de entorno dos bens tombados no bairro do Recife e sugestão de ampliação do polígono de tombamento do conjunto arquitetônico, urbanístico e paisagístico do antigo bairro do Recife, na cidade de Recife - PE. Trabalho de conclusão de curso (Especialização) - Programa de Especialização em Patrimônio PEP, IPHAN/ UNESCO, Recife, 2006.

SILVA, Jonathas Magalhães Pereira; MANETTI, Claudio; TANGARI, Vera R. Unidades de Paisagem e o processo de compreensão da forma urbana. In: COLÓQUIO QUAPA - SEL (Quadro do Paisagismo - Sistema de Espaços Livres), 6., 2011, São Paulo. Anais... São Paulo: FAU - MARANHÃO SP, 2011.

SOARES, Antonio Carlos Lobo; LOBO, Marco Aurélio Arbage. As ameaças do crescimento urbano de Belém à conservação do Parque Zoobotânico do Museu Paraense Emílio Goeldi. In: ARQUIMEMÓRIA, 3., 2008, Salvador. Anais... Salvador: IAB, UFBA, PPG-AU/ UFBA, 2008. 1 CD-ROM.

TEIXEIRA, Manuel C. A cartografia no estudo da história urbana. Seminário de História da Cidade e do Urbanismo. SHCU 1990 Seminário de História da Cidade e do Urbanismo, [S.I.], vol. 6, n. 3, 2000. Disponível em: <http://www.anpur.org.br/revista/rbeur/index.php/shcu/article/view/837/812>. Acesso em: 05 dezembro 2012.

UNESCO - UNITED NATIONS EDUCATIONAL, SCIENTIFIC AND CULTURAL ORGANIZATION . Operational Guidelines for the implementation of the World Heritage Convention. Paris: UNESCO, 2011.

\section{Cristiane V. Cabreira}

Arquiteta. Mestre e doutoranda em Arquitetura e Urbanismo pela Universidade Federal do Rio de Janeiro. É professora titular da OficinaEscola de Manguinhos, pesquisadora em Conservação Preventiva de Acervos Móveis e Imóveis e consultora da Fundação Oswaldo Cruz.

\footnotetext{
${ }^{\text {II }}$ Rosina Trevisan Ribeiro

Arquiteta. Doutora em Engenharia de Produção pela COPPE/UFRJ (2000). Professora associada da FAU/UFRJ. Coordenadora adjunta de Ensino do PROARQ - Programa de Pós-graduação em Arquitetura da FAU/UFRJ e coordenadora do Mestrado Profissional em Projeto e Patrimônio do PROARQ/FAU.UFRJ.
}

III Cláudia Barroso Krause

Arquiteta. Doutora pela Ecole Nationale Supérieure des Mines de Paris. Professora associada da UFRJ. Coordenadora do convênio CAPESCOFECUB 2010, consultora da Procel Eletrobras, consultora do Ministério de Minas e Energia. 